\title{
Caregiver training delayed admission of patients with dementia to nursing homes
}

\author{
Brodaty H, Gresham M, Luscombe G. The Prince Henry Hospital dementia caregivers' training programme. Int J Geriatr Psychiatry 1997
} $\mathrm{Fe}, ; 12: 183-92$.

\section{Objective}

To assess the long term effectiveness of an intensive training programme for caregivers of patients with dementia in delaying nursing home admission and death.

\section{Design}

Randomised controlled trial with 8 year follow up.

\section{Setting}

Psychiatric ward of a general teaching hospital in Sydney, Australia.

\section{Patients}

96 patients (mean age $70 \mathrm{y}, 52 \%$ men) who were diagnosed with dementia. 93 patients completed the study (65 had probable Alzheimer's disease, 21 had multi-infarct dementia, and 7 had other causes of dementia). Patients participated with their caregivers (93\% spouses, mean age 68 y, $54 \%$ women).

\section{Intervention}

All patients received a 10 day programme consisting of memory retraining, occupational therapy, and relaxation techniques. Caregivers were allocated to immediate 10 day caregiver training $(\mathrm{n}=33)$, training delayed for 6 months (waiting list) $(n=32)$, or no training $(n=31)$. The 10 day training consisted of informal sessions led by various health professionals on such topics as reducing distress, combating isolation, coping skills, and fitness and diet, and included social and leisure activities. Caregivers received 12 months of support and follow up interventions including telephone conferences with decreasing involvement by the coordinator and visits to the hospital at 3, 6, and 12 months for assessment and reunion times with fellow caregivers.

\section{Main outcome measures}

Deaths and nursing home admissions of patients were monitored with annual telephone calls.

\section{Main results}

Death occurred in $64 \%$ of patients whose caregivers received immediate training, 53\% whose caregivers were in the waiting list group, and $70 \%$ whose caregivers received follow up but no training. The mean times until death for the 3 groups were 65 , 68 , and 53 months, respectively. Nursing home admission rates in the 3 groups were $79 \%, 83 \%$, and $90 \%$, respectively, and the mean times to admission were 48, 36, and 28 months, respectively. When the immediate and waiting list groups were combined, 8 year survival analysis showed caregiver training delayed nursing home admission of patients $(\mathrm{p}<0.05)$ with a trend towards delaying death $(\mathrm{p}=0.08)$.

\section{Conclusion}

An intensive 10 day training programme and follow up procedure for caregivers of patients with dementia delayed admission of patients to nursing homes.

Source of funding:Australian Commonwealth Department of Health.

For article reprint: Professor H Brodaty, Academic Department of Psychogeriatrics, Prince Henry Hospital, Anzac Pde, Little Bay, Sydney, New South Wales 2036, Australia. Fax +61 293825016.

\section{Commentary}

An earlier study by Brodaty and Gresham showed that training of family caregivers of people with dementia reduced strain in the caregiver and rates of institutionalisation in the patient. ${ }^{1}$ The latter finding is supported in this report by Brodaty et al after an average follow up period of nearly 8 years. These are remarkable results from only a 10 day intervention, with follow up support restricted to 12 months.

Generally, other reports of caregiver training have indicated caregiver appreciation, but reductions in strain and institutionalisation have proved elusive. Knight et al found relatively small effects for most psychological interventions in a meta-analysis. $^{2}$ The New York study reported by Mittelman $e t a l,{ }^{3}$ and this study by Brodaty et al, are exceptions. They share a number of features: they worked mainly with spouses; the intervention was fairly intensive and individualised; family sessions were encouraged; continued peer support was facilitated; and follow up periods were extensive. This study gives a very helpful overview of the training programme and its components, which would form a good basis for any caregiver support programme. Using video tape feedback to improve caregiver patient communication is an interesting development, as is having a residential programme with caregiver and patient admitted together. The authors point out that a hospital setting is not essential; a hotel would suffice.

The new generation of pharmacological treatment approaches to dementia attract most attention, but this study is a timely reminder that simple, early, psychosocial interventions with caregivers can be cost effective in maintaining patients at home, while not increasing strain on relatives.

Bob Woods, MSc University of Wales Bangor, Wales, UK

1 Brodaty H, Gresham M. Effects of a training pragramme to reduce stress in carers of patients with dementia. BMJ 1989;299:1375-

2 Knight BG, Lutzky SM, Macofsky-Urban F. A meta-analytic review of interventions for caregiver distress: recommendations for future research. Gerontologist 1993;33:240-8.

3 Mittelman MS, Ferris SH, Shulman E, et al. A family intervention to delay nursing home family intervention to delay nursing home placement of patients with Alzheimer disease. 276:1725-31. 